\title{
Two Concepts of Effort
}

\author{
Saul Smilansky ${ }^{1}$
}

Received: 29 September 2021 / Revised: 21 January 2022 / Accepted: 15 February 2022 /

Published online: 8 March 2022

(c) The Author(s) 2022

\begin{abstract}
I distinguish between two concepts of effort, E-effort and T-effort. E-effort is the familiar one, which focuses on the experiential qualities of making an effort (such the energy and time we put into effort making, or the hardship we endure). Teleological effort (or T-effort) is the motivated and active focus on the intended purpose or goal of the effort; the aim to do what it takes to reach the target of the effort. When we make a T-effort we concentrate on the best way of getting to where we want to be, which may involve putting in less E-effort. Focusing upon T-efforts should help us both to better understand the relationship between effort and success; and to make what I call Real Efforts.
\end{abstract}

Keywords Effort $\cdot$ Success $\cdot$ Doing one's best $\cdot$ Practical reason

\section{Effort and Success}

If faucets at our house cease to function, we at once call the plumber. We want him to fix things as quickly and as well as possible (without undue expense): in other words, we care about results; we want success in the given task above all. If the plumber is so good at his job that fixing things requires little effort on his part, all the better, while if our plumber puts a huge amount of effort but all his efforts end up in failure, we won't really care about his efforts, and will invite a different plumber, whom we

If a man does his best, what else is there?

George C. Patton

Saul Smilansky

smilsaul@research.haifa.ac.il

1 Department of Philosophy, University of Haifa, Haifa 31905, Israel 
expect will be more successful. We will also not invite the unsuccessful plumber again, for all his efforts.

Wishing to forget the travails of the day, we go in the evening to see a comedy. We want to be entertained, we want the jokes to work, we want, in short, that the actors will be successful. If the acting is terrible but the actors put a lot of effort into the show, that makes it only worse. Their efforts are too apparent, the jokes seem forced; all the effort in the world cannot save them, they should probably go and do something else.

While we were seeing the show, our child was injured, and on our return we rush him to the hospital. It turns out that surgery is required. Naturally, we want every effort to be made. But here as well all that really matters is that the surgeon and her staff be successful. The urgency of our concern about effort follows from the seriousness of things, coupled with the belief that taking great care and making every effort will as a rule be conducive to success. ${ }^{1}$

So far, effort by and large seems to be either irrelevant or only of instrumental value, namely, to matter because it is conducive to success. On a closer look, we will see that effort in itself does sometimes matter to us, to some degree. We will be more willing to pay a large plumber's bill if the successful plumber had to work hard and long; we will appreciate that a surgeon strived valiantly even if she failed. Yet success remains paramount. The value of success swamps the value of effort, and the negative value of failure renders the value of effort marginal at best.

Such examples do not represent all that matters in our lives. Sometimes we seem to care primarily about effort in itself. We want people close to us to make an effort to find out how we are, to be sympathetic, and perhaps to try and help. But in large part this follows from the fact that often the relevant 'success' here just is that care and concern. When someone is our friend, he or she cares about us, and that is in itself already the success of friendship. There may not be anything further that the effort is for.

If the friend only makes an effort to care about us, or to love us, but fails, that is not really what we want, and for all the good will she has showed, and the appreciation we might have of her efforts, the friendship does not seem real. What we want is the care and love, those, again, being the marks of the success of the friendship. This second-order perspective shows us that even here success is primary.

Moreover, what is the point of effort, if not success? A person may not get the appropriate sense of 'success' into focus, but if he or she has done so, effort ought to be made for that success. ${ }^{2}$ Consider one who wishes to make efforts, but is indifferent whether these lead to success or will end in failure. It seems that, in an important sense, this person does not really understand the notion of effort. And clearly this is

\footnotetext{
${ }^{1}$ If you find out that the doctors clearly made insufficient efforts and that they were very lucky that the surgery was a medical success, you would care. So making efforts, when doing so typically matters a great deal, matters. Yet the focus remains on success.

${ }^{2}$ We do need to make room for the notion of a regulative ideal; something that you strive towards, knowing you can never achieve it but also knowing that striving for it will bring you many nearby goods that you could not get without striving for the unreachable ideal. But this need not affect our analysis.
} 
not a person whom we want along with us in life's travails. We can conclude that success is what primarily matters to us, in the context of effort. ${ }^{3}$

What should we do about this gap between effort and success? To some extent we simply have to accept it. I do think, nevertheless, that there is a partial way out, a way of breaching the chasm to some extent. Some ways of making an effort seem different in kind, and more worthy, than other ways of making an effort, and getting things clarified can be helpful. Effort is hard to understand because of the normative status of the two very different sorts of efforts. The key is to see that it is not so much the amount of effort but the kind or aspect of effort, that matters. There is a way of understanding effort in a way that incorporates its relational, intentional aspect, its focus on success as the point of effort. The way to do that is to look more closely at the notion of 'effort', and to bring it closer to the notion of 'success'. If that is done, true effort will more typically lead to success, and where it does not, the effort-makers will at least be justified in feeling that they have indeed done the best that they could. The paper will offer an analysis of the notion of effort that should also be helpful in clarifying how to make what I shall call, 'Real Efforts'. These can help bridge the gap between effort and success, and make people more effective.

The concept of effort has of course been prominent in discussions of topics such as action theory, Akrasia and free will. In recent years there has been further progress in understanding the concept of effort itself, and various dimensions of effort (see, e.g., Bradford 2015: ch.3; von Kriegstein 2017; Massin, 2017). I am not aware of any philosophical discussion that has captured the conceptual distinction I am considering.

\section{The two Concepts of Effort}

We typically think about making an effort in terms of our preoccupation, sleepless nights, and continuous labor, what we are willing to give up, the amount of hardship we endure. We can call this concept of effort "experiential effort" (or E-effort). "It was an effort to climb that mountain, I am still a bit breathless and all my muscles hurt"; "She made such an effort on that project, she worked all night"; "I know it's an effort, but you must hold on until someone comes to replace you". E-effort has both an objective and a subjective aspect: working long hours is objective, while the tiredness following such work is subjective. But both concern the experience and the difficulty of effort. This experiential sense is our main notion of effort; if we reflect on our phenomenology, it intuitively clearly seems to be the one we typically use when we report on our efforts, or ask people about their own.

There is another concept of effort, which is less commonly noted, although it as well is sometimes recognized in common speech. This we can call "teleological effort" (or T-effort). Teleological effort is the motivated and active focus on the intended purpose or goal of the effort; the aim to do what it takes to reach the target

\footnotetext{
${ }^{3}$ Of course luck may also affect success. The test of success can be a harsh one, for success is often also a result of factors beyond one's control: for example, internal inborn talents and inclinations make some much more successful than others, even if equal amounts of efforts were put in; or, external factors intervene, overrule our best efforts, and decide matters. Yet our primary concern here will be efforts that are at least in large measure within our control.
} 
of the effort. When we make a T-effort we concentrate on the best way of getting to where we want to be, and all we do is derived from that goal. "She wouldn't take No for an answer but kept thinking how she could change his mind"; "I didn't know how he would do it but I knew he would do whatever it takes to save us"; "Suddenly I saw that I must change myself or I would never be able to succeed".

E-effort and T-effort often go together: we try to do all that's needed (T-effort), and through the hard work we become tired (E-effort). Frequently the two diverge, however, and this helps us to see T-effort better, and to understand effort; and in particular its conceptual connection with success. If we continue to think of 'effort' only as E-effort, there will remain too great a chasm between effort and success. For example, many people are obsessed with work, put in sleepless nights, devote an enormous amount of continuous energy, sacrifice a great deal - yet fail, while others are successful with much less E-effort. Beyond lamenting the unfairness of life, we might try some modification, in the success-related direction, of our dominant notion of effort. I propose that we think of 'Real Effort' in a more demanding, successfocused way. In other words, I suggest that we think of Real Effort primarily in terms of T-effort. This does not mean that we should give up the notion of E-effort, but that (i) we recognize T-effort much more than we do at present, and (ii) normatively give it priority in most contexts of understanding effort.

\section{Some Ways of Distinguishing the two Concepts}

Let us consider some of the important aspects of effort-making. This will help us to see further that there are two very different concepts of effort involved, and the importance of the second, teleological one.

One way of distinguishing among the two concepts of effort concerns the very things a person does. The manifestly untalented musician, singer, or actor who continues to pursue the dream of an artistic career may be falling off her feet from the effort: in terms of E-effort, she is supreme. But in terms of T-effort, she is very deficient, and in my judgment no Real Effort is being made here. If there is no real chance of success, there is no way reliably to focus actions towards success (although see discussion of "hopelessness" below). Likewise, the under-performing investor in equities who is in the wrong job because psychologically he cannot tolerate risk and loss may work so hard that in effect he ceases having a life outside of those countless tense hours that he spends at his work-desk; making E-efforts has taken over his life, and he is fast approaching a mental break-down. But he is not making a T-effort, and failing to put Real Effort, properly understood, because he persists in his job rather than leaving to do something he is capable of doing well. Only if we think of effort in terms of the contrast between E-effort and T-effort, and see the dominance of the second, will we understand what is happening in such examples, and what should be done to improve matters. A square peg ought above all to look for a square hole, and all the seeming effort of trying to fit itself into a round hole only indicates (if there is an alternative) that there is a problem here in terms of effort.

Of course people may do things because they have no choice, or for the sake of doing them, as a hobby, or because they simply enjoy the process; that is fine, but it is 
not our topic here. Differently, we must leave room for the outlying case, such as the stubborn innovator, who seemingly has every indication that his efforts are hopeless, but still persists, up to ultimate triumph. We also need to take account of the actual differences between the likelihood of success in the different fields. On certain matters (such as the search for some types of medical cures) the likelihood of success may be dubious, but still it might be worthwhile to take up the chase, in the light of what is at stake, and because ruling out certain possibilities through failure may in itself be informative. Setting out to make a living by writing novels is inherently riskier than wishing to make a living through being an accountant, but I do not wish to say that no one ought to attempt to write novels. The difficulty of doing so successfully merely strengthens the need to avoid this direction if a person lacks the requisite ability. I of course acknowledge that sometimes one doesn't know whether one has an ability until one tries and fails, and that while making efforts, sometimes abilities are developed. When all such examples and considerations are set aside, however, we remain with the multitude of people who are commonly thought to be making an effort, but this is a misperception; they are only making E-efforts, but are striving in the wrong direction, and "that is no way to make an effort" (i.e. normatively, a Real Effort).

The main way in which effort-making shows itself within work is through the focus on the end result, on the product that is the 'success' in the area of pursuit, and on the means to achieve it. We are all too familiar with people who do not seek good advice, do not learn from the success of others or from their own repeated failures, do not pursue alternative ways that might lead to success, and do not learn about themselves and change themselves so as to be better geared for success. Rather, such people remain set in their not-too-successful ways, oblivious to the advice of others, to indicators of failure, and to the potential for increasing their chances, factors that are all around them. There may be in such cases a preponderance of E-effort, but very little T-effort, and it is the latter that matters in most contexts such as we are considering. Such people should also not be thought of as making a Real Effort. By valuing E-effort over T-effort we inadvertently promote all sorts of failure. But if we valued T-effort more than E-effort (and we needn't neglect the value of E-effort so long as we relegate it beneath T-effort) we will promote success.

Once again, we need to make distinctions and allowances. The person who can perhaps succeed but does not fully do so on account of moral scruples may be admirable as compared to the unscrupulous who are in fact more successful: success that is bought at a morally unacceptable price becomes unraveled. Seeking to remain decent does not, as a rule, mean that one is not making a Real Effort. Likewise, people often do not succeed because they are overwhelmed by factors beyond their control, such as illness, unexpected competition, or the discrimination and exclusion of others. Just as it is easy to fool ourselves into believing that we have done "all we can", it is all too easy to judge others harshly without recognizing that their lack of outward success may not tell us anything about them except that they were victims of unlucky circumstances, or of the ill will of others. When all such examples are set aside, we remain, once again, with the many people who commonly think of themselves, and are considered by others, to be making great efforts, but since they 
are persistently deficient in their T-efforts, ought not to be thought of, normatively, as making Real Efforts.

Making a T-effort requires different things, depending upon the sort of tasks one has. When people rise in organizational hierarchies, usually they do not reduce their effort-making. In fact, they are likely to be making only more E-efforts, trying to cope with the new circumstances. Yet making T-efforts goes beyond putting in the hours and pushing harder. The new position will have new characteristics. For instance, it may require working in an environment of inherently greater uncertainly, with more concern about the future, much less direct control over the product, and with more time devoted to managing other people. Adjusting to the new requirements means realizing the need for change and then changing oneself so as to be a successful T-effort maker in the new situation.

A particular indicator of the sort of effort that is being displayed concerns seeking ways of achieving a given level of success with fewer efforts. The mark of the person who is truly making an effort is that he or she are trying to do more through less E-effort, namely, to be reducing the level of effort (per given task). Those who do not reflect on the ways in which they can better organize their energy and time, so as to reduce their E- effort, who do not make the constant T-effort to question their methods, seek short cuts and, in fact, look for the easy way to get rid of tasks, are clearly not making optimal efforts. It is questionable whether they should be thought to be making a Real Effort; the normative evaluation of effort which I shall explain ahead. They may well be making a huge effort in terms of E-effort, however, which indicates how very different the two concepts of effort are.

This feature of effort-making is understandably often hidden from us. For, the effort at expending less energy is shared by the true T-effort-makers (as construed here), and by the lazy and uncaring. But under close observation we can distinguish the two categories. The true effort-makers championed here might be just as happy at being able to perform tasks by doing less, but this will be because of the better way that they have found to attain the result, which remains their focus. Moreover, they will already be targeting the next task, and utilize the saved energy, time, and any other resources for further successes, while the lazy will only seek to rest. Hence, the true T-effort makers will typically be openly joyful at the saved time or energy, for they have succeeded in improving the means of success, and happily can go on now to do more, while the lazy and uncaring will typically hide it, lest they be asked to do more.

In a further twist, it is sometimes the lazy that ought to be thought of as being those who have made the most Real Effort. Laziness is, occasionally, the mother of invention, and then, perversely, the otherwise lazy person who has grabbed the chance of doing something more efficiently becomes successful. In terms of the ordinary E-effort notion of effort this manifestly successful agent has not made much of an effort, but this should just cause us to be skeptical about the ordinary adherence to E-effort. Usually such a case will be an indication that even if laziness might have motivated this person, he or she was not in an important sense lazy: for example, that he or she expended some effort in a success-tracking direction, thinking harder than others how to save human energy, resources, or time. Seeking to save on E-effort, he invested his E-efforts wisely, as a good T-effort maker. Perhaps there has to be some 
minimal E-effort component if we are to say that an effort occurred, but unlike the T-effort component, the E-effort can be quite limited.

Sometimes, indeed, making an E-effort as commonly understood is the wrong way of going about attaining success. Certain Far-Eastern belief systems have especially developed our recognition of such cases (see, for instance, Herrigel 1972). Of course, in order to reach the desired state of effortless success one typically has to make a great deal of E-effort. It is significant and supportive of my case, however, that even in such cases, once mastery is achieved, effort needs to be made in the right (but counter-intuitive, i.e. with as little E-effort as possible) way.

The issue of enjoyment is also sometimes a distinguishing mark here. Anyone committed to success in difficult matters should be ready to do things that are hard to do, and that it is natural not to want to do. The relationship between liking one's labor and making an effort is complex. Some projects are inherently tiresome, repetitive, painful, or even humiliating, hence are very hard to like. Nevertheless, one additional mark of Real Effort is the striving after a situation where one likes (much of) one's effort-making. This follows to some extent from previous points: if one chooses rightly at what to make an effort, and handles his or efforts wisely, the effort is likely to be more pleasant to do, and success is more likely to occur (hence further motivating efforts). A T-effort, success-oriented approach to effort-making, will aim to achieve a close connection between effort and satisfaction: ideally, one will not feel how hard one is working because the labor is rewarding (one's work will often be as a hobby to one), and even when it is not, effort-making in itself will give its satisfactions (see Csikszentmihalyi 1975).

There is here no contradiction between Real Effort-making and its seeming opposites, playfulness and joy. While within an ethos of E-effort one gets credit for suffering, for the hardship involved in making the effort, T-effort welcomes combining pleasure and effort. A moralizing cult of suffering cannot dependably and over time generate effective efforts, and liking one's project and one's effort-making is important in success, and hence in the true making of an effort.

The distinction between the quantity and quality of effort is crucial here: E-effort focuses upon quantity, while T-effort points to the qualitative aspects of effort-making. Often people think of effort simply as doing more, but as we saw, more may be less, either because the direction of effort is misguided and will not lead to the desired success; or because a better way to proceed now would be not to do more of the same, but to stop, reflect, and improve our means; or, even, because the best thing to do is simply to rest and recover our strength for the greater efforts of another day. (For a masterly, reflective discussion of the ways to combine effort and success, see Ogilvy 2004.)

\section{Opting for Real Effort}

All of this does not mean that we need not have sympathy for ordinary E-effort makers of various sorts, who turn out not to be deserving of the epitaph 'Real Effort maker' by my proposed standards. One can make real E-efforts (which are genuine efforts) without making Real Efforts. Human beings who are constantly being disap- 
pointed and end up with nothing to show for their hopes, concern, energy output, and time, often should be pitied. Humanly, their sacrifices and misery do not disappear even if they are impotent. Like a car running on neutral, they lose twice; expanding energy, and getting nowhere. When such people have harmed only themselves, they often merit sympathy. This does not, however, mean that such unsuccessful people deserve the recognition that T-effort commonly provides; rather, they should be helped to recognize that they have not been doing what Real Effort requires, and pointed in the right direction.

Quite reasonably we are likely to retain a feeling of unease: the sense of 'effort' that has been normatively rejected here (E-effort) is, after all, our primary commonsense one, and the idea that someone who puts out so much concern, worry, energy, sacrifice, and anguish (as the commonly-conceived E-effort-makers do), is not, in a sense, really making an effort, may seem absurd. The supreme mythical effort-maker is Sisyphus, who, we recall, gets nowhere and hence fails the T-effort test. I may be charged with confusing effectiveness with effort: effort is effort merely because of its "effort-like" qualities, it might be said, and it remains effort even if it is not made in an ideal success-tracking fashion. We all have our limitations, we must make decisions when our knowledge is uncertain; we try and cope in the world. Moreover, my view seems insensitive or even cruel: is it not enough that people fail despite their overwhelming E-efforts, that I would want to come along and, by talking of Real Effort, in a sense deny them the making of the very effort?

Put differently, on the one hand we have the thought that 'effort' just is concern, worry, tiredness, pain, etc. In other words, we may think only of E-effort. It would be incredible not to give credit for making an effort to one who clearly is doing so much. But on the other hand, if my arguments are convincing, these persons' actions should not in themselves suffice to constitute Real Effort making, and in fact will often accompany behavior patterns that we ought not to consider to be such. I claim, first, that we need to speak of two concepts of effort rather than of one, and as long as we know which one we are speaking of at a given time, we have made progress. I also claim that we can go further if we accept the revisionist normative view of 'effort' which focuses upon T-effort, and recognize that, in most contexts, it is the more significant sense. I am proposing the adoption of a notion of Real Effort that can contain both species of the genuine effort, but in a weighted way, giving priority to T-effort.

Real Effort is an evaluative rather than a merely descriptive concept, and some of the evaluations or judgments are likely to be unpleasant. We may be more easily reconciled to this view if we see that adequate evaluations will frequently be nuanced. An E-effort maker who nevertheless fails to make a true T-effort may be merely pretending to care about making an effort, or she may not be dishonest towards others but only self-deceptive, or she might be authentically trying to do all she can on every level, but misdirected in her efforts. Which of these is the case of course matters. Moreover, effort is usually a matter of degree, and its evaluation is often influenced by comparison to others. No one is a perfect T-effort maker, and we should sympathize with those who attempt to be, even if they do not fully manage this. We would also naturally be more lenient and more inclined to give credit for E-efforts when dealing with children or those inherently challenged in their understanding and effectiveness. A fuller discussion would also need to distinguish between the subjec- 
tive and objective elements of effort, and would be open to the consideration of the details of particular cases.

Moreover, we do not want to limit goal-oriented T-effort to highly competent, reflective, innovative and exertion-saving behaviour. The implication would be that stupid or untalented people cannot make a real (goal-directed) effort. This is clearly false (by existing linguistic standards) and, primarily, also would not be a plausible stipulation, because it would blur the crucial distinction here between a mediocre plumber that gets the job done in the end and somebody exerting himself and just creating a mess. Here we should allow three kinds of cases:

1. Strenuous, but largely pointless effort not properly focussing on success.

2. Seriously goal-directed effort; which includes (a): pedestrian, unimaginative varieties; and (b) uncommonly talented, intelligently reflecting on how to be more productive. Both $2 \mathrm{a}$ and $2 \mathrm{~b}$ would be versions of T-effort, although $2 \mathrm{~b}$ would of course be better. ${ }^{4}$

Why opt for my stipulated sense of Real Effort, and not speak about 'effort' in the ordinary E-effort ways, and then add that effort is simply better when it is not pointless, counterproductive, and the like? To do so comes at a price. Conceptually, much of the notion of effort is intentional, and requires the connection with the reasonable tracking of success (albeit with the reservations made above taken into account). Continuing only with a notion of effort that lacks the close attachment to success seems to me misguided: if we forget what effort is for, we misunderstand the nature of effort. Recall the examples at the beginning of this paper. It is telling that we are particularly ready to give credit for E-efforts in the case of children or severely challenged adults.

Moreover, the way we view this is not merely theoretical, but matters greatly to how we will view our lives, for our notion of the good life, and for our success. And the commonsense view hides the useful insights that we can gain by taking the view of effort being proposed. It is all too common, for instance, to find people who know that their attainments will improve if they take time off, but nevertheless remain in an ever-vigilant obsessive mania of hard work. They may exhibit a puritanical devotion to effort-making, but it is not a real pursuit of effort, for it lacks the proper reflective, flexible, responsiveness to the actual conditions for success. The more E-effort such people make, after a certain point, the less T-effort, and hence the less success. This is not the way to make an effort.

It matters of course what 'success' is, what one aims at. This topic is beyond our present scope, and surely invites an expansive and pluralistic treatment. But whatever our view is likely to be here, it makes sense to take note of the points made, as a way of improving one's chances of achieving whatever it is that one wants to achieve. If we realize the importance of T-effort we will focus on it, and this should improve all the aspects that can lead us to success, which we saw above, such as wisely deciding

\footnotetext{
${ }^{4}$ T-effort need not be conscious, but focusing on some level seems required. Hence, while one can clearly succeed by accident, there is a sense in which one cannot make T-efforts by accident (although one can accidentally end up making a T-effort).
} 
on what to pursue and giving up when we see that the pursuit is misguided, focusing on the quality rather than the quantity of effort, trying to succeed with less E-efforts, pacing our E-efforts rather than engaging in them compulsively, attempting to modify our attitudes and enjoy our efforts so as to make them less experientially taxing, and the like. Our second-person and third-person attitudes and reactions as well may change, and we can better guide others towards improving in these respects. Often, our dogged emphasis on E-efforts pushes people towards blind effort-for-effort's sake, futile efforts, and failure.

Finally, we can conceive of extreme ideals that would see any 'successes' in such a way that achieving it would be considered detrimental to the good life. Perhaps passivity and the death of ambition are being recommended. In such cases possibly the notion of success is merely being reversed and some of my points will retain their sting. In any case, the attractiveness of such views should remain marginal. Often, when efforts are not being made, or even when great efforts are being made but this is not done in a reliably success-tracking manner, then behind such seemingly senseless incompetence in fact lies ambivalence about success, or even the desire to fail.

\section{Conclusions}

There are two distinct, very different, and often contrastive concepts of effort: E-effort, which is broadly about the experience of difficulty and hardship in intentional tryings; and T-effort, which is about focusing on doing what can be done in order to attain the goal of the effort; the dogged pursuit of the means for success. The criterion of someone making a T-effort is not their experience of discomfort, what they are as it were "paying", but the degree to which their activity is focussed upon and adapted to the goal of the effort.

Conceptually, there is an internal relation between T-effort and success. To make an effort is for one's action to be oriented towards successful completion of the task. And normatively, we need to emphasize T-effort, which is much more closely tied to success: if you continue doing something you are bad at (and not in the context of mere play or the like, or if you have no choice), this is not really making an effort. Similarly, if you are not focused on success and on the realistic means for it, on what it takes to succeed, you aren't really making an effort. Real Effort is qualitative and not quantitative. Moreover, often you should be focused on achieving as much success as possible with as little effort as possible (namely, with as little E-effort as possible), for that reserves your energies, resources, and time so as to be able to pursue further success. Finally, accepting the E-effort in effort-making, but trying to affirm and even love what one is doing so that effort-making will become less of an E-effort, are also good ideas, when possible, for those who want to better their T-efforts. There is, then, much more to effort than E-effort: in choosing one's goals wisely, adjusting one's means in a success-sensitive way, concentrating on the quality of the efforts rather than the quantity, and sometimes even in making less of an E-effort, or getting oneself to a state where one's efforts do not feel like E-efforts.

The approach being proposed, as exemplified in these points, offers a novel, normative, and somewhat revisionary understanding of what making an effort is. In 
most contexts, making an effort should not be thought of primarily as E-effort, which seems to be our typical view, but as T-effort. Further work needs to be done in exploring this direction. But already we can understand that much of what goes on in the world under the description of 'effort', fails by this (T-effort) test. It only appears to be real effort, but because it lacks the proper focus on success, it is not only, often, a predictable failure in terms of success; it fails as effort as well. ${ }^{5}$

Open Access This article is licensed under a Creative Commons Attribution 4.0 International License, which permits use, sharing, adaptation, distribution and reproduction in any medium or format, as long as you give appropriate credit to the original author(s) and the source, provide a link to the Creative Commons licence, and indicate if changes were made. The images or other third party material in this article are included in the article's Creative Commons licence, unless indicated otherwise in a credit line to the material. If material is not included in the article's Creative Commons licence and your intended use is not permitted by statutory regulation or exceeds the permitted use, you will need to obtain permission directly from the copyright holder. To view a copy of this licence, visit http://creativecommons.org/ licenses/by/4.0/.

\section{References}

Bradford, G. (2015). Achievement. Oxford: Oxford University Press

Csikszentmihalyi, M. (1975). Beyond Boredom and Anxiety: Experiencing Flow in Work and Play. SanFrancisco: Jossey-Bass

Herrigel, E. (1972). Zen in the Art of Archery. London: Routledge \& Kegan Paul

Massin, O. (2017). "Towards a definition of efforts". Motivation Science, 3(3), 230-259

Ogilvy, D. (2004). Confessions of an Advertising Man. London: Southbank Publishing

von Kriegstein, H. (2017). "Effort and achievement". Utilitas, 29, 27-51

Publisher's Note Springer Nature remains neutral with regard to jurisdictional claims in published maps and institutional affiliations.

\footnotetext{
${ }^{5}$ I am very greateful to Aaron Ben-Zeev, Iddo Landau, Sam Lebens, Jonathan Smilansky, Daniel Statman, and two anonymous referees for Philosophia, for helpful comments on drafts of this paper.
} 